УДК 339.13

$10.17213 / 2075-2067-2020-5-141-151$

\title{
ВОПРОСЫ КЛИЕНТООРИЕНТИРОВАННОСТИ БИЗНЕСА В РОССИИ: ПОЧЕМУ НЕ ВСЕ ПРОГРАММЫ ЛОЯЛЬНОСТИ УСПЕШНЫ
}

\author{
(C) 2020 г. В. А. Бондаренко, Н. В. Гузенко, Р. М. Межаев \\ Ростовский государственный экономический университет (РИНХ), \\ 2. Ростов-на-Дону, Россия
}

Целью исследования является обоснование сущности и специффики оценки клиентоориентированности и клиентоцентризма, являющимися значимым направлением в современном маркетинге компаний, а также выявление ключевых факторов при выстраивании работы с потребителями, влияющих на результативность клиентских программ, которые выступают продолжением и воплощением ориентации бизнеса на клиентов.

Методологическая база исследования. В рамках исследования вопросов клиентоориентированности бизнеса в России и аналитики причин отсутствия успешной реализации программ лояльности мы опираемся на рассмотрение профильных литературных источников по направлению клиентоцентризма в маркетинговой деятельности компаний в России и за рубежом, такэе опираемся на результаты эмпирических исследований сложсившейся практики ведения бизнеса в направлении клиентоориентации в В2В и В2С сегментах. Использованы методы описания, сравнения, сопоставления, анализа и синтеза полученной информачии.

Результаты исследования. Одним из важных результатов является выявление у компаний в городах федерального значения большей степени ориентации на клиентов в связи с сильной конкурентной борьбой, связанной с высокой концентрацией бизнеса. При этом именно сегмент В2С является флагманом осуществляемых клиентоориентированных инициатив, воплощчаемых в реальность. Приходим к выводу, что проявляются тенденции, способствующие переходу от формального клиентоцентризма к реальному, что позволит обеспечить эффективность применяемых программ клиентской лояльности для тех организаций, которые будут укреплять свои рыночные позициии.

Перспективу исследования составляет доказательный анализ компаний в России по критерию ориентации на потребителей и выявлению необходимости перехода от формального клиенточентризма к реальному, что обеспечит результативность програми клиентской лояльности для тех организачий, которые будут укреплять свои рыночные позиции.

Ключевые слова: клиентоориентированность; клиентоиентризм; маркетинг компаний; клиентские программь.

\section{BUSINESS CUSTOMER QUESTIONS IN RUSSIA: WHY ARE NOT ALL LOYALTY PROGRAMS SUCCESSFUL}

\author{
(C) 2020 V. A. Bondarenko, N. V. Guzenko, R. M. Mezhaev
}

\section{Rostov State University of Economics (RSUE), Rostov-on-Don, Russia}

The purpose of the study is to substantiate the essence and specifics of assessing customer focus and customer centrism, which are a significant direction in modern marketing of companies, 
as well as identifying key factors in building work with consumers that affect the effectiveness of client programs, which are a continuation and embodiment of business orientation towards customers.

The methodological base of the study. As part of the study of the issues of customer focus of business in Russia and the analysis of the reasons for the lack of successful implementation of loyalty programs, we rely on the consideration of specialized literary sources in the direction of customer centrism in the marketing activities of companies in Russia and abroad, we also rely on the results of empirical studies of the established practice of doing business in the direction of customer orientation in B2B and B2C segments. Methods of description, comparison, comparison, analysis and synthesis of the information obtained were used.

The results of the study. One of the important results is the identification of companies in federal cities with a greater degree of customer orientation, due to the strong competition associated with a high concentration of business. At the same time, it is the B2C segment that is the flagship of ongoing customer-oriented initiatives that are being implemented. We come to the conclusion that tendencies are emerging that contribute to the transition from formal client-centrism to real, which will ensure the effectiveness of the applied client loyalty programs for those organizations that will strengthen their market positions.

The prospect of the study compiles an evidence-based analysis of companies in Russia according to the criterion of customer orientation and identifying the need to move from formal customer centrism to real, which will ensure the effectiveness of customer loyalty programs for those organizations that will strengthen their market positions.

Key words: customer focus; customer centrism; company marketing; client programs.

Введение. Интерес к ориентации на запросы потребителей присутствовал в маркетинговой деятельности изначально, поскольку в условиях работы в конкурентной среде именно понимание потребностей своих потенциальных клиентов и вариант их наилучшего удовлетворения при одновременном соблюдении интересов компании является залогом успеха для предприятий и организаций.

В настоящее время в теории и практике компаний исследуются и применяются подходы по построению программ лояльности, являющиеся проявлением ориентации бизнеса на интересы клиентов, нацеленные на выстраивание длительных взаимовыгодных отношений с целевой аудиторией $[9,10,13$, 23]. Однако, далеко не все конструируемые программы лояльности успешны на практике и приводят к искомому результату, что вызывает интерес к исследованию клиентоориентации бизнеса и пониманию того, является ли она для большинства организаций на российском рынке реальной или в большинстве случаев представляет собой декларацию о намерениях и формально транслируемые тезисы, не в полной мере сопрягаемые с предпринимаемыми бизнесом действиями $[11,12]$.

Обсуждение. Такие исследователи, как О. Ойнер, Е. Пантелеева подчеркивают, что восприятие клиентоориентированности бизнесом эволюционировало и прошло ряд взаимосвязанных стадий от трансформации фокуса на продукте к фокусировке усилий на потребителе, ориентации на целевой рынок, представленный ключевыми клиентами, и наконец, так называемой клиентоцентричности в маркетинговой деятельности [16].

Говоря о клиентоориентированности, ряд авторов именует ее маркетинговой ориентацией бизнеса [27], другие говорят об общей ориентации на рынок и на целевые сегменты [5].

Зарубежные исследователи, такие как Дж. Нарвер, С. Слейтер, Д. Маклахлан, а также Р. Дешпанде, Дж. Фарли, Ф. Уэбстер и Ф. Джейкоб, концентрировали внимание на анализе экономического эффекта от ведения клиентоориентированного бизнеса на всех типах рынков $[1,2,3,5]$. 
Группа отечественных и зарубежных ученых в своих работах актуализирует применение клиентоориентированного подхода для бизнес-структур на рынках развитых и развивающихся стран, дифференцируя отличия в предпринимаемых решениях, продиктованные нестабильностью ситуации, характерной для развивающихся рынков [6, 18, 19, 22, 25].

Для оценки клиентоориентированности в компании исследователями разработаны и используются различные модели шкал, в основу которых положены определенные объекты анализа, определенные метрики, их количество и применение на рынках развитых и развивающихся государств. Общая характеристика данных подходов проиллюстрирована в таблице 1 .

Первая указанная шкала связана с направлением обеспечения клиентоориентированности компании, исходя из соответствующей направленности действий ее сотрудников и того факта, что сотрудники лояльны к организации-работодателю и по этой причине настроены на полноценное удовлетворение запросов клиентов.

Вторая шкала нацелена на оценку ориентации бизнеса на клиентов компании в сравнении, например, с установкой на межфирменное сотрудничество или конкурентное взаимодействие. Третья шкала содержит большое количество индикаторов, что препятствует ее применению на всех типах рын- ков, так как сбор информации для валидации ситуации на ее основе слишком трудоемок.

Четвертая и пятая шкалы во многом похожи на третью и используют аналогичные индикаторы для оценки клиентоориентированности бизнеса. Две последние шкалы в практическом плане не тестировались на рынках развивающихся стран.

Также укажем, что для оценки общей клиентоориентированности бизнеса принято выделять бизнес-процессы, характеризующие эту деятельность. По мнению ряда исследователей, в числе данных бизнес-процессов лидируют следующие элементы:

- агрегирование основной информации, характеризующей потребителей [14];

- аналитика полученной информации о клиентах и их рыночном поведении [15];

- внутрифирменные коммуникации, способствующие пониманию ситуации с удовлетворением потребителей $[4,16,24]$;

- выведение на рынок новых продуктов и сервисов [16, 20, 24, 27];

- обучение сотрудников, взаимодействующих с потребителями, рост их мотивации $[7,26]$;

- выстраивание взаимоотношений с клиентами, как со стратегическими партнерами $[7,8,11,27]$.

Различные подходы и отмечаемая исследователями разница в осуществлении клиентоориентированных решений на рынках развитых и развивающихся стран, к которым

Основные шкалы, используемые для оценки

Таблица 1 клиентоориентированности компании $[1,2,5,21,22]$

\begin{tabular}{|l|c|c|c|}
\hline Характеристики & Объект анализа & $\begin{array}{c}\text { Количество } \\
\text { нндикаторов } \\
\text { оценки }\end{array}$ & $\begin{array}{c}\text { Тестирование } \\
\text { на рынках } \\
\text { развивающихся } \\
\text { стран }\end{array}$ \\
\hline SOCO & Сотрудники & 7 & да \\
\hline MKTOR & Компания & 6 & да \\
\hline MARKOR & Компания & 32 & да \\
\hline 9-факторная шкала & Компания & 9 & да \\
\hline MORTN & Компания & 10 & да \\
\hline CUSTOR & Компания & 17 & нет \\
\hline $\begin{array}{l}\text { Проактивная/реактивная/рыночная } \\
\text { ориентация }\end{array}$ & Компания & 8 & нет \\
\hline
\end{tabular}


относятся в том числе и государства БРИКС, предопределяют актуальность аналитического рассмотрения результатов эмпирических исследований относительно проявляющейся клиенториентации бизнеса в России.

Результаты. Характеризуя существующие данные проведенных ранее эмпирических исследований, позволяющих понять ситуацию в части клиентоориентированности бизнеса в России, приведем результаты масштабного маркетингового исследования, проведенного в 2014 г. в городах федерального значения - Москве и Санкт-Петербурге, а также других городах России, расположенных в регионах. В исследовании принимали участие 313 компаний, работающих на потребительских и промышленных рынках [12].

Согласно полученным О. Гулаковой, В. Ребязиной, М. Смирновой результатам, компании в России по критерию ориентации на клиентов можно разделить на 5 укрупненных кластеров (рисунок 1).

Полученные результаты свидетельствуют о наличии высокой ориентации на удовлетворение потребительских запросов у немногим более $30 \%$ организаций, тогда как, например, $20 \%$ компаний декларируют такой характер деятельности без подтверждения его в реальности, $6 \%$ организаций демонстрируют низкую ориентацию своего бизнеса на нужды и запрос целевой аудитории.

Целесообразно также привести данные относительно территориального размещения компаний, попадающих в тот или иной основной кластер по параметру ориентации на потребителей (рисунок 2).

Согласно представленным данным видно, что большая ориентация на клиентов проявляется у компаний в городах федерального значения, где выше концентрация бизнеса и более жестко протекает конкурентная борьба.

Важным промежуточным выводом представляется также то, что компании, декларирующие в качестве основной ценности интересы клиента и не придерживающиеся этой установки, на самом деле занимаются копированием модели поведения конкурентов, которая кажется им успешной. Например, они ведут клиентскую базу, но не применяют полученные данные о предпочтениях и поведении потребителей для выведения востребованных ими сервисов и продуктов.

Согласно данным другого эмпирического исследования, проведенного в 2017 г.

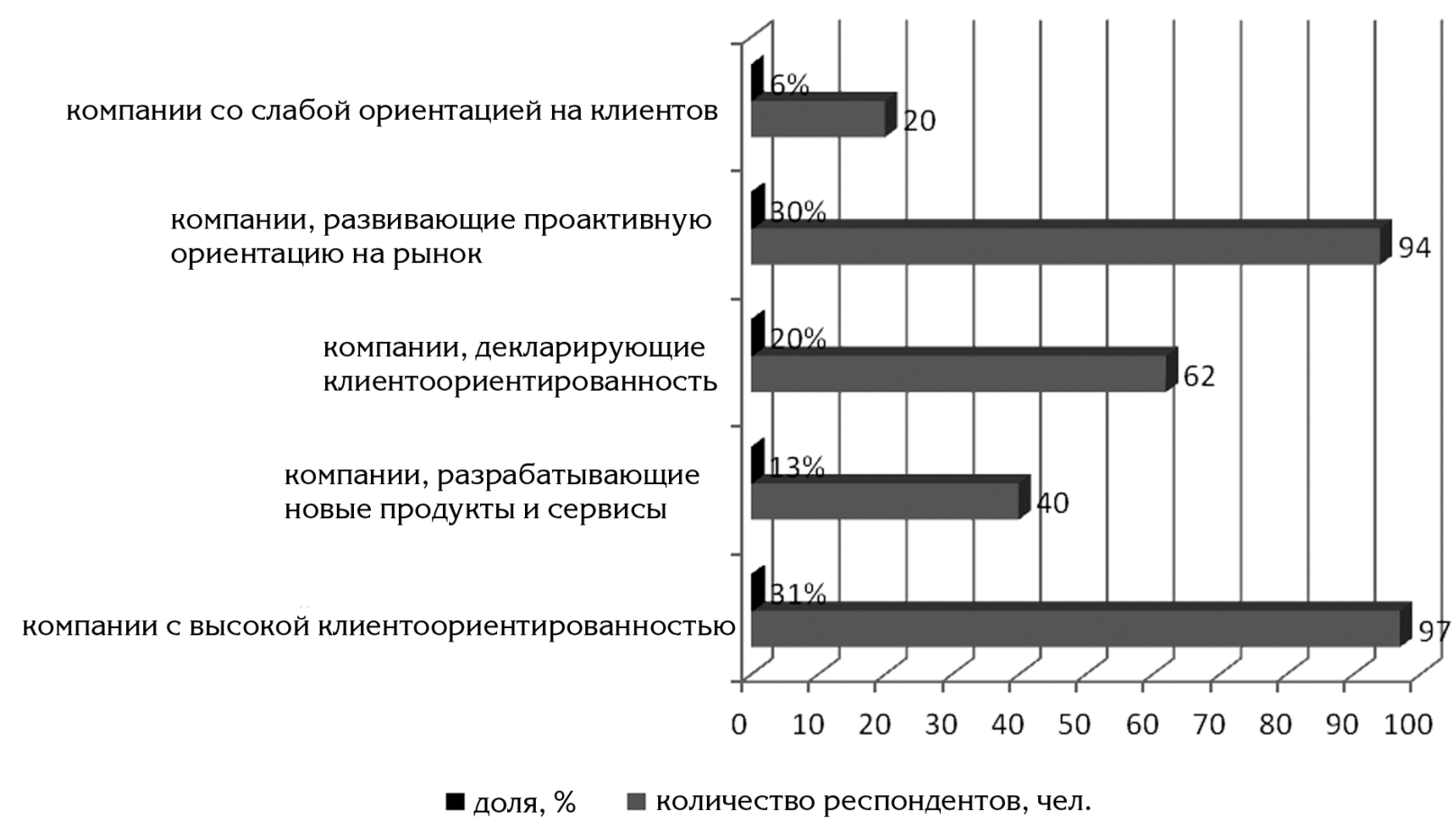

Рис. 1. Распределение компаний в России по пяти основных кластерам, исходя из критерия ориентации на потребителей в 2014 г., чел, \% [11] 


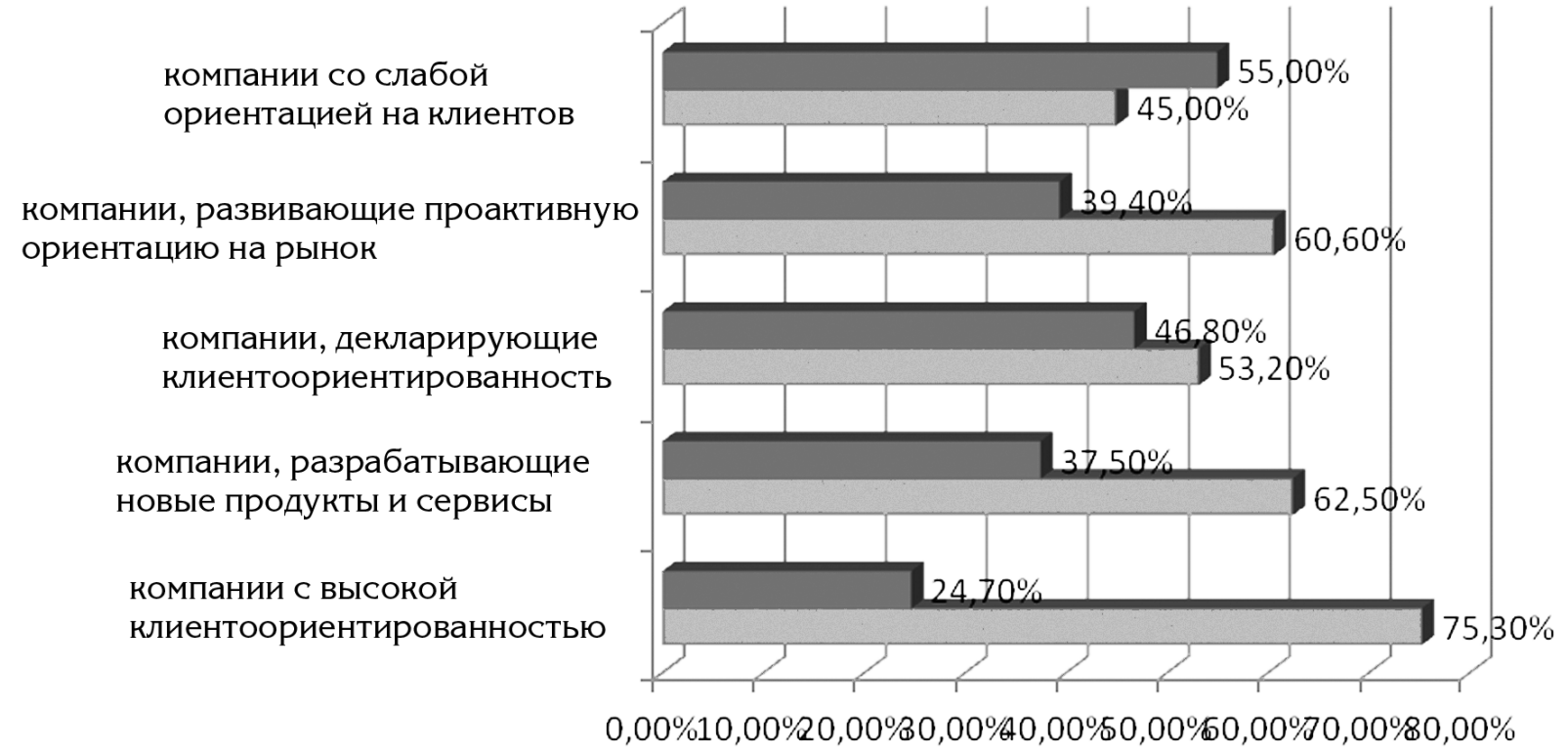

п другие регионы $\square$ города федерального значения

Рис. 2. Распределение компаний

в городах федерального значения и в регионах по основным кластерам, \% (согласно данным О. Гулаковой, В. Ребязиной, М. Смирновой) [11]

учеными О. Гулаковой, В. Ребязиной в виде глубинного интервью с сотрудниками компаний, работающих на российском рынке (в городах федерального значения и в регионах), были получены данные о наиболее популярных в российском бизнесе бизнес-процессах, свидетельствующих об ориентации на потребителей [11].

Территориальное расположение компаний, сотрудники которых участвовали в интервью, а также принадлежность бизнеса к В2С или В2В проиллюстрированы на рисунках 3 и 4.

Приведенные данные также подтверждают наличие широкого интереса к клиенториентации в городах федерального значения как в сегменте В2B, так и В2C.

Данные о востребованности определенных бизнес-процессов, подтверждающих ориентацию бизнеса на потребителей, приведены на рисунке 5.

Полученные результаты свидетельствуют, с одной стороны, о высокой (по крайней мере, анонсируемой или декларируемой) ориентации на клиентов российских компаний. С другой стороны, они коррелируют с информаций о низкой ориентации такого рода у $6 \%$ компаний и декларируемой форме такой ориентации у $30 \%$, так как среди значимых бизнес-процессов только $53 \%$ опрошенных отнесли выведение на рынок тех товаров и сервисов, которые выступают отражением клиентских запросов. Соответственно, остальные представители компаний проявляют именно декларируемую клиенториентацию. Они собирают необходимые сведения о потребителях, но, скорее, как дань моде или по-

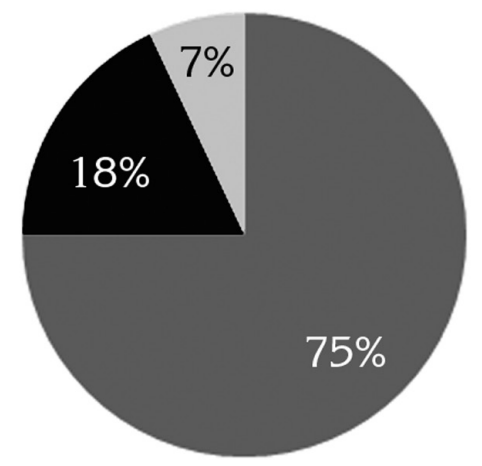

Москва

Санкт-Петербург

другие регионы

Рис. 3. Территориальное расположение компаний - участниц исследования, \% [11] 


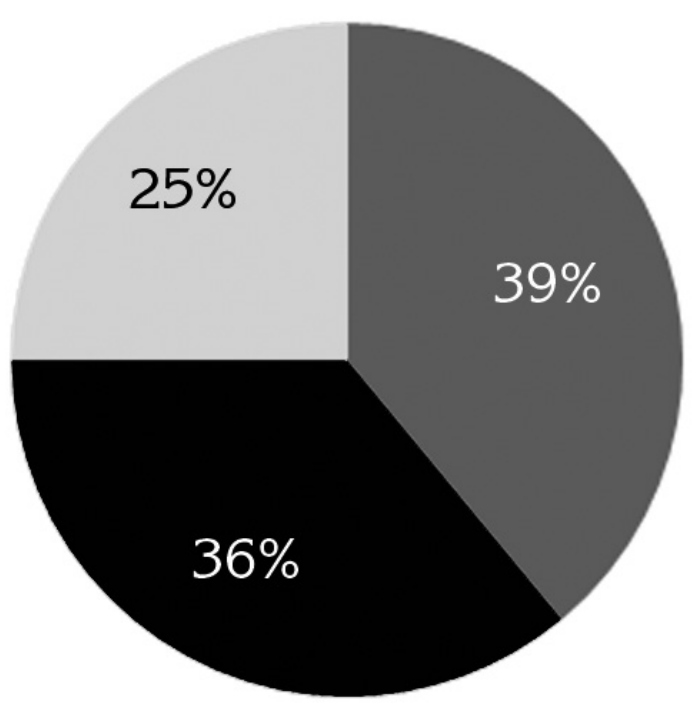

\section{$\mathrm{B} 2 \mathrm{~B} \square \mathrm{B} 2 \mathrm{C} \square \mathrm{B} 2 \mathrm{~B}$ и B2C}

Рис. 4. Принадлежность компаний к В2В или В2С сегменту, \% [11]

выстраивание взаимоотношений с клиентами, как со стратегическими партнерами

обучение сотрудников, взаимодействующих с потребителями, рост их мотивации

выведение на рынок новых продуктов и сервисов

внутрифирменные коммуникации, способствующие пониманию ситуации с удовлетворением потребителей

аналитика полученной информации о клиентах и их рыночном поведении

агрегирование основной информации, характеризующей потребителей тому, что так делают другие, а необходимых дальнейших действий не предпринимают.

Можно также отметить, что согласно результатам другого эмпирического исследования в В2С сегменте (очевидно, из-за высокого уровня конкуренции) бизнес в большей степени проявляет интерес к клиентоцентризму, ориентации на потребителя. К условным ТОР-5 в данном случае относят такие признаки, как понимание и акцентирование на потребностях клиентов, нацеленность на соответствие их ожиданиям, нацеленность на постоянство обратной связи, составление прогнозов развития клиентских потребностей, нацеленность на высокую степень удовлетворенности клиентских запросов [17].

Это позволяет предположить, что именно сегмент В2С в настоящее время в России является флагманом осуществляемых клиентоориентированных инициатив, воплощаемых в реальность, а не просто декларируемых в анонсе работы компаний.

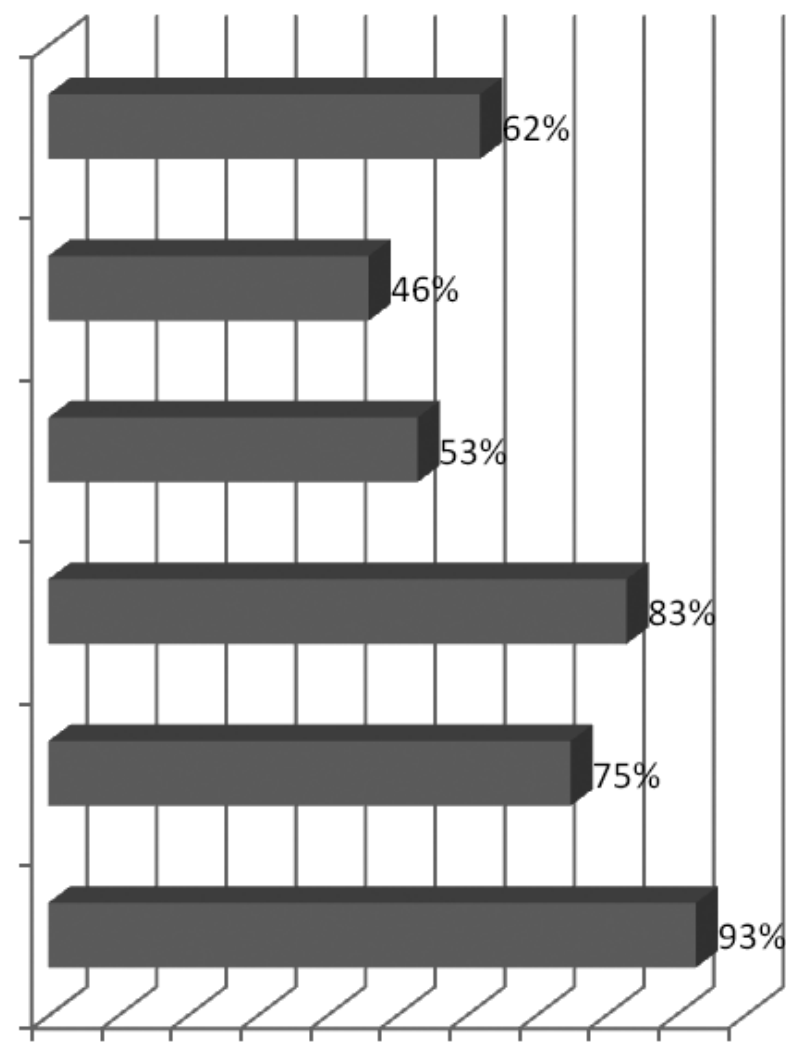

0\% 10\%20\%30\%40\%50\%60\%70\%80\%90\%100\%

Рис. 5. Востребованность определенных бизнес-процессов, подтверждающих ориентацию бизнеса на потребителей в российских компаниях, \% (согласно исследованию О. Гулаковой, В. Ребязиной) [12] 
Заключение. Клиентоориентированность и клиентоцентризм являются значимым направлением в современном маркетинге компаний, что подтверждается большим количеством научных разработок и прикладным интересом со стороны бизнеса, функционирующего в высоко конкурентной среде. Это актуализирует применение программ лояльности, которые выступают продолжением и воплощением клиентоориентированности компаний. Тем не менее, далеко не все клиентские программы являются успешными, что свидетельствует о неверно определенных ориентирах при выстраивании работы с потребителями.

Результаты эмпирических исследований свидетельствуют о наличии у ряда организаций декларируемой формальной клиенториентации. В В2С сегменте организаций, проявляющих реальную ориентацию на запросы потребителей, больше, поскольку на рынке представлено большее количество игроков и выше конкурентная борьба за клиентский спрос. Полагаем, что, учитывая практическую ситуацию, в В2В сегменте будут проявляться те же тенденции, способствующие переходу от формального клиентоцентризма к реальному, что приведет к результативности программ клиентской лояльности для тех организаций, которые будут укреплять свои рыночные позиции.

\section{Литература}

1. Deshpande R., Farley J.U. Measuring Market Orientation: Generalization, Synthesis// Journal of Market-Focused Management. 1998. - Vol. 2. - №3. - P. 213-232.

2. Deshpande R., Farley J. U., Webster F.E. Corporate Culture Customer Orientation, Innovativeness in Japanese Firms: A Quadrad Analysis // Journal of marketing. - 1993. Vol.57. — №1. - P. 23-37.

3. JacobF. Preparing Industrial Suppliers for Customer Integration // Industrial Marketing Management. - 2006. - Vol. 35. - №1. P. 45-56.

4. Kohli A.K., Jaworski B.J., Kumar A. MARKOR: A measure of market orientation// Journal of Marketing Research. - 1993. №30 (4). - P. 467-477.

5. Narver J. C., Slater S. F., MacLachlanD.L. Responsive and proactive market orientation and new-product success. // The Journal of Product Innovation Management. - 2004. №21 (5). - P. 334-347.

6. Roersen M.J., KraaijenbrinkJ., Groen A.J. Marketing ignorance, the validity of Narver and Slater's MKTOR scale in high-tech Russian firms// Journal of Product Innovation Management. 2013. - №30 (3). - P. 545-559.

7. Saxe R., Weitz B.A. The SOCO scale: A measure of the customer orientation of salespeople // Journal of Marketing Research. 1982. — №19 (3). - P. 343-351.

8. Бусаркина В.В. Понятие клиентоориентированности предприятия и проблемы ее оценки [Электронный ресурс] // Проблемы современной экономики №4 (24). - Режим доступа: http://www.m-economy.ru/art. php?nArtId=1660 (Дата обращения: 10.04.2020).

9. Васин Ю. В., Лаврентьев Л.Г., Самсонов А. В. Эффективные программы лояльности. Как привлечь и удержать клиентов. - М.: Альпина Паблишер, 2007. - 152 с.

10. Герия И.А.Программы лояльности и оценка их эффективности // Управление и экономика в XXI веке. — 2015. - №1. C. $47-52$.

11. Гулакова О.В., Ребязина В.А., Смирнова М.М. Специфика клиентоориентированности компаний на российском рынке: результаты эмпирического исследования // Вестник СПбГУ. Серия: Менеджмент. 2015. - №4. - C. 39-73.

12. Гулакова О.В., Ребязина В.А. Клиентоориентированность компаний на российском рынке: декларация или реальность// Вестник СПбГУ. Серия: Менеджмент. 2017. - Т. 16. Вып. 3. - С. 398-417.

13. Добровидова М. А. Эффективные технологии повышения лояльности потребителей // Маркетинг и маркетинговые исследования. - 2005. - №3. - С. 48-53.

14. Ламбен Ж.-Ж. Менеджмент, ориентированный на рынок. Стратегический и операционный маркетинг. - СПб.: Питер, 2007. $800 \mathrm{c}$.

15. Лошков B. Клиентоориентированность, в чем суть? [Электронный ресурс] // Бизнес-обучение в России. — 2008. - Режим доступа: http:// www.rosbo.ru/articles.php?cat_ $\mathrm{id}=2$ (Дата обращения: 17.05.2015).

16. Ойнер О. К., Латылшева Л. С. Влияние рыночно-ориентированного поведения ком- 
паний на результативность бизнеса// X Международная научная конференция по проблемам развития экономики и общества: в 3 кн. Кн. 2. - М.: ГУ-ВШЭ, 2009. - С. 287-296.

17. Ойнер О. К., Пантелеева Е. К. Признаки клиентоориентированного подхода к управлению FMCG-компанией на российском рынке // Управленец. - 2019. - №2. - С. 11-20.

18. Попов Н. И., Третьяк О.А. Экономические факторы низкой клиентоориентированности компаний в странах БРИК // Российский журнал менеджмента. - 2014. T. 12. 一 №1. - С. 109-138.

19. Ребязина В.А., Давий А.О. Маркетинговые практики: теоретические подходы к определению и понимание представителями российских компаний // Вестн. Московского ун-та. Сер. 6. Экономика. — 2014. №6. - C. 97-117.

20. Резник Г.А., Яшина О.В. Клиентоориентированность корпорации как вызов времени // Проблемы современной экономики. 2013. - №2. - С. 171-175.

21. Рожков А.Г. Ориентация компании на клиента: опыт практического исследования // Вестник Уральского федерального унта. Сер. Экономика и управление. - 2012. №4. - C. 20-31.

22. Рожков А.Г., Ребязина В.А., Смирнова M.M. Ориентация компании на клиента: результаты эмпирической проверки на примере российского рынка // Российский журнал менеджмента. - 2014. - Т. 12. - №3. C. $33-58$.

23. Савина A.A. «Поймать лояльность» в социальную сеть // Маркетинговые коммуникации. - 2009. - №05 (53). - C. 258-262.

24. Семенов И.В., Кубахов П.С., Малкова Т.Г. Ориентация на рынок российских компаний: постановка проблемы, исследование и перспективы // Маркетинг и маркетинговые исследования. - 2009. - №5. C. 360-378.

25. Фролов В.Г., Любимова М.В., Савицкая Т.В., Храмова Т.Ю., Чемоданова Ю.В., Чекулишева T.K. Методы оценки эффективности управления организацией при реализации клиентоориентированного подхода // Российское предпринимательство. 2014. 一 №16 (262) - С. 16-26.

26. Шерешева М. Ю., Костанян А. А. Клиентоориентированность персонала в госу- дарственных организациях здравоохранения России // Вестник Санкт-Петербургского университета. Серия: Менеджмент. - 2015. №4 - С. 74-114.

27. Юлдашева О.У., Ширшова О.И. Маркетинговая ориентация компаний: методология исследования и измерения // Вестник Научно-исследовательского центра корпоративного права, управления и венчурного инвестирования Сыктывкарского государственного университета. - 2013. - №3. - С. 96-112.

\section{References}

1. Deshpande R., Farley J.U. Measuring Market Orientation: Generalization, Synthesis // Journal of Market-Focused Management. 1998. - Vol. 2. - №3. - P. 213-232.

2. Deshpande R., Farley J. U., Webster F.E. Corporate Culture Customer Orientation, Innovativeness in Japanese Firms: A Quadrad Analysis // Journal of marketing. — 1993. Vol. 57. - №1. - P. 23-37.

3. Jacob F. Preparing Industrial Suppliers for Customer Integration // Industrial Marketing Management. - 2006. — Vol. 35. — №1. - P.45-56.

4. Kohli A.K., Jaworski B.J., Kumar A. MARKOR: A measure of market orientation// Journal of Marketing Research. - 1993. №30 (4). - P. 467-477.

5. Narver J. C., Slater S. F., MacLachlanD.L. Responsive and proactive market orientation and new-product success. // The Journal of Product Innovation Management. — 2004. №21 (5). - P. 334-347.

6. Roersen M.J., Kraaijenbrink J., Groen A.J. Marketing ignorance, the validity of Narver and Slater's MKTOR scale in high-tech Russian firms // Journal of Product Innovation Management. — 2013. - №30 (3). - P. 545-559.

7. Saxe R., Weitz B.A. The SOCO scale: A measure of the customer orientation of salespeople // Journal of Marketing Research. 1982. — №19 (3). - P. 343-351.

8. Busarkina V.V. Ponjatie klientoorientirovannosti predprijatija i problemy ee ocenki [The Concept of customer orientation of the enterprise and problems of its evaluation] [Jelektronnyj resurs] // Problemy sovremennoj jekonomiki [Problems of modern economy] №4(24). - URL: http://www.m-economy.ru/art. php?nArtId=1660 (Date accessed: 10.04.2020). 
9. Vasin Ju. V., Lavrent'ev L. G., Samsonov A. $V$. Jeffektivnye programmy lojal'nosti. Kak privlech'i uderzhat' klientov [Effective loyalty programs. How to attract and retain customers]. Moscow: Al'pina Pablisher, 2007. - 152 p.

10. Gerija I.A. Programmy lojal'nosti i ocenka ih jeffektivnosti [Loyalty Programs and their effectiveness evaluation] // Upravlenie i jekonomika v XXI veke [Management and Economics in the XXI century]. — 2015. - №1. Pp. 47-52.

11. Gulakova O.V., Rebjazina V.A., Smirnova M.M. Specifika klientoorientirovannosti kompanij na rossijskom rynke: rezul'taty jempiricheskogo issledovanija [Specifics of client orientation of companies in the Russian market: results of an empirical study] // Vestnik SPbGU. Serija: Menedzhment [Bulletin of St. Petersburg State University. Management series]. 2015. — №4. - Pp. 39-73.

12. Gulakova O.V., Rebjazina V.A. Klientoorientirovannost' kompanij na rossijskom rynke: deklaracija ili real'nost' [Client Orientation of companies in the Russian market: Declaration or reality] // Vestnik SPbGU. Serija: Menedzhment [Bulletin of St. Petersburg State University. Series Management]. — 2017. Vol. 16. Issue. 3. - Pp. 398-417.

13. Dobrovidova M.A. Jeffektivnye tehnologii povyshenija lojal'nosti potrebitelej [Effective technologies for increasing consumer loyalty] // Marketing i marketingovye issledovanija [Marketing and marketing research]. 2005. - №3. - Pp. 48-53.

14. Lamben Zh.-Zh. Menedzhment, orientirovannyj na rynok. Strategicheskij i operacionnyj marketing [Market-oriented Management. Strategic and operational marketing]. - SaintPetersburg: Piter, 2007. - 800 p.

15. Loshkov $V$. Klientoorientirovannost', $\mathrm{v}$ chem sut'? [Customer Orientation, what is the point?] [Jelektronnyj resurs] // Biznes-obuchenie $\mathrm{v}$ Rossii [Business training in Russia]. 2008. - URL: http:// www.rosbo.ru/articles. php?cat_id=2 (Date accessed: 17.05.2015).

16. Ojner O.K., Latysheva L.S. Vlijanie rynochno-orientirovannogo povedenija kompanij na rezul'tativnost' biznesa [Influence of marketoriented behavior of companies on business performance]. // X Mezhdunarodnaja nauchnaja konferencija po problemam razvitija jekonomiki i obshhestva [X international scientific confer- ence on problems of economic and social development]. Vol. 2. - Moscow: GU-VShJe, 2009. - Pp. 287-296.

17. Ojner O.K., Panteleeva E.K. Priznaki klientoorientirovannogo podhoda $\mathrm{k}$ upravleniju FMCG-kompaniej na rossijskom rynke [Signs of a client-oriented approach to managing an FMCG company on the Russian market] // Upravlenec [Manager]. - 2019. - №2. - Pp. 11-20.

18. Popov N.I., Tret'jak O.A. Jekonomicheskie faktory nizkoj klientoorientirovannosti kompanij $\mathrm{v}$ stranah BRIK [Economic factors of low client-oriented companies in the BRIC countries] // Rossijskij zhurnal menedzhmenta [Russian journal of management]. — 2014. Vol. 12. - №1. - Pp. 109-138.

19. Rebjazina V.A., Davij A.O. Marketingovye praktiki: teoreticheskie podhody k opredeleniju i ponimanie predstaviteljami rossijskih kompanij [Marketing practices: theoretical approaches to definition and understanding by representatives of Russian companies] // Vestn. Moskovskogo un-ta. Ser. 6. Jekonomika [Bulletin of Moscow Univ. Ser. 6. Economics]. 2014. — №6. — Pp. 97-117.

20. Reznik G.A., Jashina O.V. Klientoorientirovannost' korporacii kak vyzov vremeni [Customer Orientation of the Corporation as a challenge of time] // Problemy sovremennoj jekonomiki [Problems of modern economy]. 2013. - №2. - Pp. 171-175.

21. RozhkovA.G. Orientacija kompanii na klienta: opyt prakticheskogo issledovanija [Company Orientation to the client: experience of practical research] // Vestnik Ural'skogo federal'nogo un-ta. Ser. Jekonomika i upravlenie [Bulletin of the Ural Federal University. Ser. Economics and management]. — 2012. №4. - Pp. 20-31.

22. RozhkovA.G., Rebjazina V.A., Smirnova M.M. Orientacija kompanii na klienta: rezul'taty jempiricheskoj proverki na primere rossijskogo rynka [Orientation of the company to the client: results of empirical testing on the example of the Russian market] // Rossijskij zhurnal menedzhmenta [Russian journal of management]. - 2014. - Vol. 12. — №3. - Pp. 33-58.

23. Savina A.A. «Pojmat' lojal'nost'» v social'nuju set' [ «Catch loyalty» in social network] // Marketingovye kommunikacii [Marketing communications]. — 2009. — №05 (53). Pp. 258-262. 
24. Semenov I.V., Kubahov P.S., Malkova $T$. G. Orientacija na rynok rossijskih kompanij: postanovka problemy, issledovanie i perspektivy [Market Orientation of Russian companies: statement of problems, research and prospects] // Marketing i marketingovye issledovanija [Marketing and marketing research]. — 2009. №5. - Pp. 360-378.

25. Frolov V.G., Ljubimova M.V., Savickaja T. V., Hramova T. Ju., Chemodanova Ju. V., Chekulisheva T.K. Metody ocenki jeffektivnosti upravlenija organizaciej pri realizacii klientoorientirovannogo podhoda [Methods of evaluating the effectiveness of management of the organization in implementation of customer-oriented approach] // Rossijskoe predprinimatel'stvo [Journal of Russian entrepreneurship]. — 2014. №16 (262) - Pp. 16-26.

26. Sheresheva M. Ju., Kostanjan A.A. Klientoorientirovannost' personala $\mathrm{v}$ gosudarst- vennyh organizacijah zdravoohranenija Rossii [Customer Orientation of personnel in state healthcare organizations of Russia] // Vestnik Sankt-Peterburgskogo universiteta. Serija: Menedzhment [Bulletin of Saint Petersburg University. Management series]. — 2015. — №4 Pp. 74-114.

27. Juldasheva O. U., Shirshova O.I. Marketingovaja orientacija kompanij: metodologija issledovanija i izmerenija [Marketing orientation of companies: research and measurement methodology] // Vestnik Nauchnoissledovatel'skogo centra korporativnogo prava, upravlenija i venchurnogo investirovanija Syktyvkarskogo gosudarstvennogo universiteta [Bulletin Of the research center for corporate law, management and venture investment of Syktyvkar state University]. — 2013. №3. - Pp. 96-112.

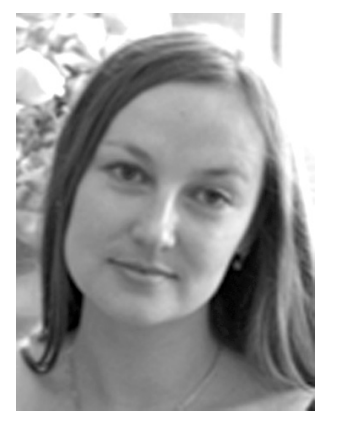

Бондаренко Виктория Андреевна - доктор экономических наук, доцент Ростовского государственного экономического университета (РИНХ).

Bondarenko Victoria Andreevna - Doctor of Economic Sciences, Associate Professor, Rostov State University of Economics (RSUE).

344002, г. Ростов-на-Дону, ул. Б. Садовая, 69 69 B. Sadovaya st., 344002, Rostov-on-Don, Russia

E-mail: b14v@yandex.ru 


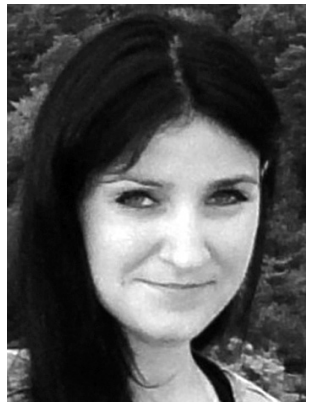

Гузенко Наталья Владимировна - кандидат экономических наук, доцент Ростовского государственного экономического университета (РИНХ).

Guzenko Natalia Vladimirovna - Candidate of Economic Sciences, Associate Professor, Rostov State University of Economics (RSUE).

344002, г. Ростов-на-Дону, ул. Б. Садовая, 69

69 B. Sadovaya st., 344002, Rostov-on-Don, Russia

E-mail: musamav@mail.ru

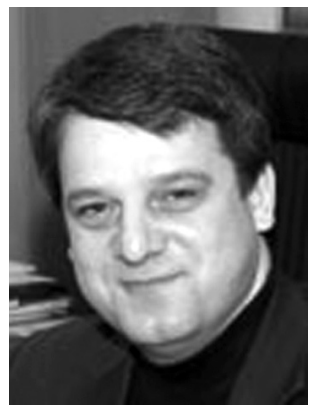

Межаев Руслан Махмудович - кандидат экономических наук, доцент Ростовского государственного экономического университета (РИНХ).

Mezhaev Ruslan Makhmudovich - Candidate of Economic Sciences, Associate Professor, Rostov State University of Economics (RSUE).

344002, г. Ростов-на-Дону, ул. Б. Садовая, 69

69 B. Sadovaya st., 344002, Rostov-on-Don, Russia

E-mail: b14v@yandex.ru 